\title{
Practical Example of Introductory Engineering Education Based on the Design Process and Teaching Methodology Using a Gyro Bicycle
}

\author{
Yoshikazu HIGA ${ }^{1}$ (iD) \\ Ken SHIMOJIMA ${ }^{2}$ \\ ${ }^{1,2}$ Department of Mechanical Systems Engineering, National Institute of Technology, Okinawa College, Japan \\ 'Email:v.higa@okinawa-ct.ac.jp Tel: +81980554118 \\ Email:k_shimo@olinawa-ct.ac.jp Tel: +81980554122
}

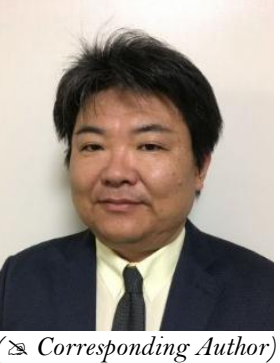

\begin{abstract}
This report describes a workshop on the Dynamics of Machinery based on the fabrication of a gyro- bicycle in a summer school program for junior high school students. The workshop was conducted by engineering students who had completed "Creative Research", an engineering design course at the National Institute of Technology, Okinawa College (Okinawa KOSEN). The paper reports on the approximately one month run-up to the workshop and describes the classroom scene on the day of presentation. At the close of the workshop, participants were asked to complete an evaluative questionnaire. Responses were quite positive with respect to the lecture slides, guidance and workshop content. On the instructor side, it was confirmed that to promote student understanding, communications and teaching skills are crucial, although it has a passive impression for the achievement level of the workshop.
\end{abstract}

Keywords: Introductory engineering education, Creative research, Design process, Teaching skill.

Citation | Yoshikazu HIGA; Ken SHIMOJIMA (2018). Practical Example of Introductory Engineering Education Based on the Design Process and Teaching Methodology Using a Gyro Bicycle. Asian Journal of Education and Training, 4(1): 51-55. History:

Received: 22 December 2017

Revised: 7 February 2018

Accepted: 12 February 2018

Published: 14 February 2018

Licensed: This work is licensed under a Creative Commons Attribution 3.0 License (cc) EV

Publisher:Asian Online Journal Publishing Group
Contribution/Acknowledgement: Both authors contributed to the conception and design of the study. The authors would like to express our sincere thanks to emeritus Prof. Junji MATSUE for his contribution to Summer School and its planning.

Funding: This study received no specific financial support.

Competing Interests: The authors declare that they have no conflict of interests.

Transparency: The authors confirm that the manuscript is an honest, accurate, and transparent account of the study was reported; that no vital features of the study have been omitted; and that any discrepancies from the study as planned have been explained.

Ethical: This study follows all ethical practices during writing.

\section{Contents}

1. Introduction: What is "Creative Research"?

2. Student Approach to "Creative Research"

3. Results of Questionnaire

4. Conclusions 


\section{Introduction: What is “Creative Research"?}

The first national college of technology (KOSEN) was established in 1962. Since that time, KOSEN alumni have been recognized by both industry and academia as skilled engineers possessing not only a high level of knowledge but also impressive hands-on skills that have contributed significantly to the field. Today, KOSEN education is offered at 51 colleges ( 55 campuses) across Japan, forming, in close cooperation with industry, a unique and successful higher-education system for young students from the age of 15 (Kobatake, 2013; EDU-Port Japan, 2017). The early practical engineering education offered by KOSEN schools has been highly acclaimed by OECD member countries (Newby et al., 2009) and has received the attention of many rising countries throughout the world.

The National Institute of Technology, Okinawa College (Okinawa KOSEN) is situated in Okinawa prefecture on the southernmost island of Japan. The college was founded in 2002, becoming the 55th and youngest national college of technology in Japan. We have a five-year general course consisting of Mechanical Systems Engineering, Information and Communication Systems Engineering, Media Information Engineering and Biological Resources Engineering, as well as a two-year advanced course for Creative Systems Engineering majors. In March of 2017, we held our ninth graduation and our seventh advanced course graduation. The mission of our school is "To contribute to the development of society by training trusted, innovative-minded engineers." Throughout their five years of technical training, Okinawa KOSEN students have the opportunity to become truly creative engineers (Araki, 2010; National Institute of Technology Okinawa College, 2017). In order to advance this purpose, we have introduced unique educational elements such as the Okinawa KOSEN Seminar (Higa et al., 2010) the Creative Seminar, the Creative Industry Seminar, internships, and so on. In this paper, we highlight "Creative Research", an engineering design course that students are able to complete during their first year. This class enables students to experience the research project/process as part of their introductory education and is designed to promote practical engineering.

In order to highlight our technical specialties, the college has organized numerous activities, events and promotions. As one of these promotional events, Summer School offers an opportunity to learn about our school's educational offerings by allowing individuals to experience the technical education presented by each department. Since 2011, the authors' department, Mechanical Systems Engineering, has conducted technical education in such classes as Engineering Materials, Heat Engine Dynamics, Mechanisms, and the Dynamics of Machines. In 2014, classes in Mechanisms, Control Engineering, Thermal and Fluids Engineering, and the Dynamics of Machines were offered. As described in this paper, the Dynamics of Machines class produced the "self-standing" (gyro-) bicycle (Murata, 2011).

Several years ago, six third-year students in Mechanical Systems Engineering who were finishing their "Creative Research" class introduced the Dynamics of Machines in summer school by using the assembly of a gyrobicycle as a way to teach the subject. To conduct such a class, it was necessary to identify and explore the necessary talents, including communication skills, teaching and coaching skills, task competences, and activities that would be needed. This paper shows the lecture and the activities planned by the students. The results of a questionnaire given to participants following the lecture provided the means to assess the effectiveness of the class.

\section{Student Approach to "Creative Research"}

\subsection{Planning and Discussion of the Class}

To encourage discussion and indicate the goal of the lecture, we prepared a syllabus for the class. Table 1 shows the contents of the class as outlined in the syllabus. The number of hours indicates the actual time spent. All sessions were conducted after school, outside the regular curriculum. The six students who had completed their "Creative Research" course discussed how to build the gyro bicycle and how to use the fabrication process to teach the Dynamics of Machines. At the end of each lesson, we identified any problems that would need to be addressed in the next lesson. These were shared by all members of the team in the form of a daily report. Including the above reports, grades were evaluated based on teaching method (e.g., slide data); questionnaire responses served as a means of self-evaluation.

As shown in Table 2, the elements for making a gyro-bicycle were enumerated by the students. They set the workshop goals as follows: 1) Conduct two one-hour lessons for 18 students; 2) Make and test a gyro-bicycle during the course of the workshop. It was decided that only some of the necessary activities (those indicated by * in the table) would be conducted during the workshop; the other work would be prepared in advance.

Table-1. Contents and outline of the class.

\begin{tabular}{l|c|l}
\hline \multicolumn{1}{c|}{ Items } & Hours & \multicolumn{1}{c}{ Contents and outline of class } \\
\hline Examine instruction method & 2 & $\begin{array}{l}\text { Examine instruction method for making gyro-bicycle related to the Dynamics } \\
\text { of Machines and list the necessary parts and their purchase through team } \\
\text { discussion. }\end{array}$ \\
\hline $\begin{array}{l}\text { Assembly production and } \\
\text { reexamination }\end{array}$ & 10 & $\begin{array}{l}\text { Machining and cutting based on the parts list. } \\
\text { Reexamine the instruction method and make the documents for the class. }\end{array}$ \\
\hline Demonstration & 4 & Demonstration, including pre-post-preparation \\
\hline Self-evaluation & 1 & Self-evaluation associated with the class \\
\hline
\end{tabular}

Table-2. Elements and units for making a gyro-bicycle, including pre-process and machining.

\begin{tabular}{l|l}
\hline Process of cutting wood for the gyro bicycle frame & Hole opening process for motor base \\
\hline Hole opening process at front wheel position & Plastic bending process for motor base \\
\hline *1 Installation of rear wheel (tightening with wood screw) & ${ }^{*} 4$ Installation of motor on its base \\
\hline Hole opening process for the front wheel caster & Process of cutting circular plate from acrylic board \\
\hline$*_{2}$ Installation of acrylic circular plate into motor axis & Installation of pinion gear in circular plate \\
\hline$*^{*}$ Installation of front wheel (tightening + double nut of bolt) & ${ }^{*} 5$ Wiring the battery box to the motor \\
\hline Process of cutting metal sheet for motor base & ${ }^{*} 6$ Attaching the battery box to the wood frame \\
\hline
\end{tabular}




\subsection{The Day of the Summer School Workshop}

Figure 1 shows the lecture room scene on the day of the workshop. As pictured, three junior high participants and one tutor who had finished his "Creative Research" course sat at each table in the room. At the start of the workshop, an outline of the process was provided by an instructor using a projector at the front of the lecture room. The process was then politely demonstrated and explained by the tutors at each table as the participants proceeded to construct their own gyro-bicycle. The tutors monitored the progress of the work and provided guidance on an individual basis.

\section{Results of Questionnaire}

\subsection{Questionnaire for Summer School Participants after the Lecture}

To assess opinions before and after the workshop, we administered a questionnaire to all who participated. The questionnaire sought to measure student impressions of the level of difficulty of the practical work involved, before and after the class, and the practice and lecture performance of the tutors. Participants were also asked to provide a self-evaluation of their finished product and to indicate their degree of understanding of why a moving bicycle remains upright. Figure 2 shows a radar chart of questionnaire results relating to the activities in Table 2. The square and triangle symbols indicate participant impressions before and after the lecture, respectively. The scores show the average responses of 30 participants (there were 30 valid responses; the total number of participants was 35); a lower score indicates greater difficulty. From the chart, it is apparent that prior to the start of the workshop the hard work such as installation of the front wheel gave the impression of being relatively easy. On the other hand, some of the simpler work, as we predicted, was perceived as more difficult.

Figure 3 shows the results of the questionnaire given to participants at the conclusion of the workshop. Responses to Question 1,2 and 3, which focus on the lecture and the coaching by the tutors, were generally quite favorable. Given their responses to Question 4, which involves a self-evaluation of the gyro-bicycle construction process, the participants appeared to be very satisfied, apart from approximately $10 \%$ of the students who answered "average" or "dissatisfied." Participant understanding of the mechanical phenomena associated with the gyro effect also appeared to be quite good. Additionally, the authors checked participant impressions of the tutors in the form of free description. There were many appreciative comments mentioning that the tutors 1) prepared parts in advance, including difficult processing, 2) made appropriate comments and suggestions, and 3) taught carefully and politely.
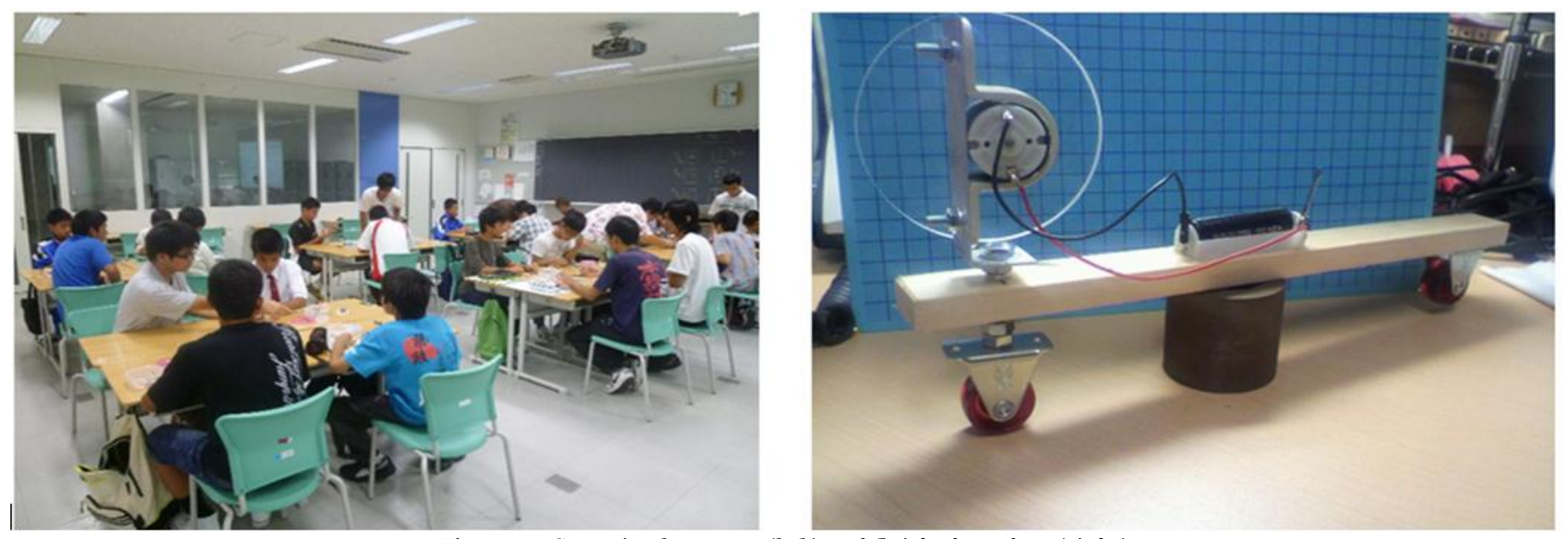

Figure-1. Scene in classroom (left) and finished product (right).

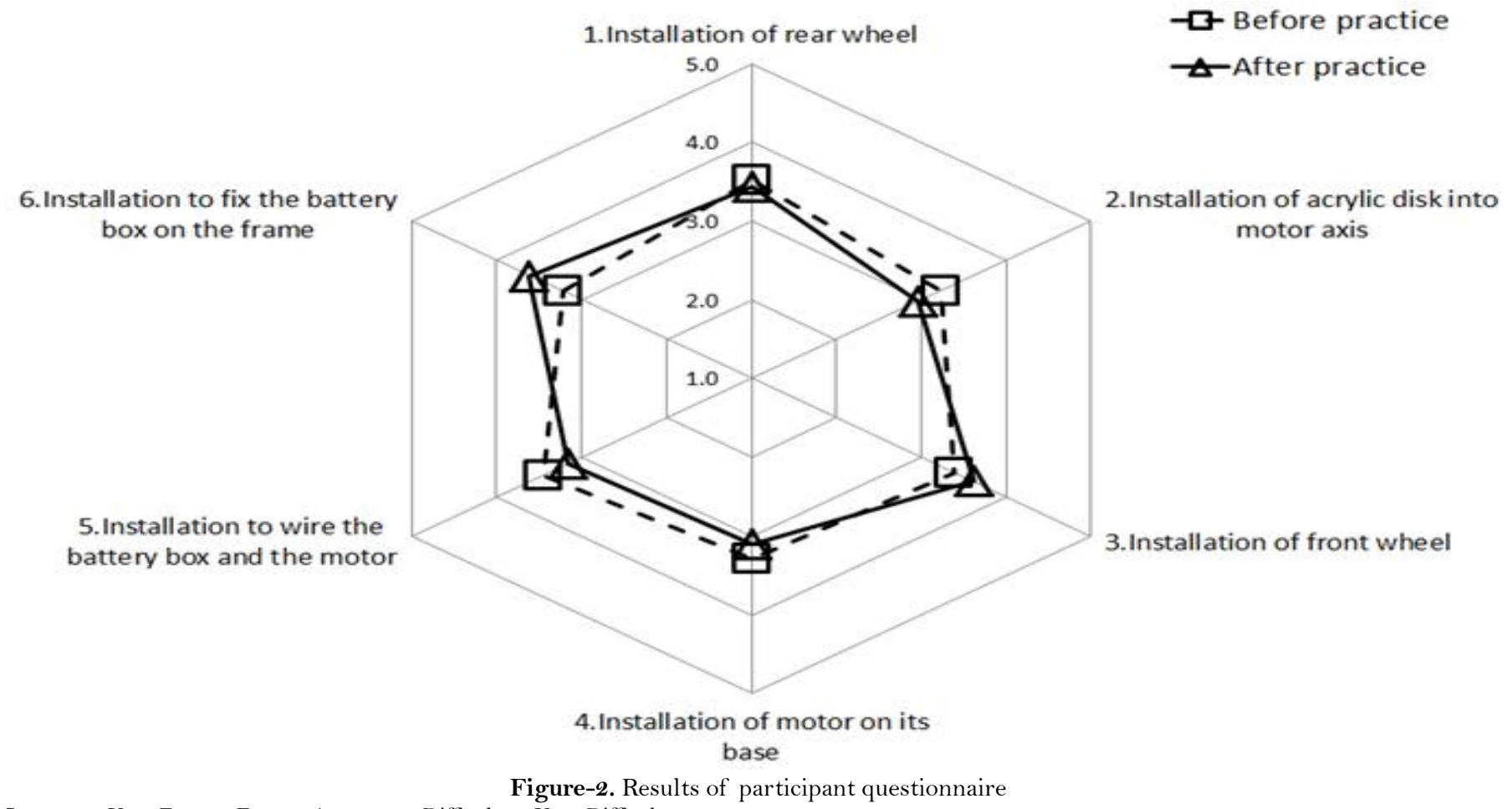

Source: 5: Very Easy, 4: Easy, 3: Average, 2: Difficult, 1: Very Difficult 


\subsection{Questionnaire for the Tutors Following the Lecture}

As shown in Table 1, the tutors held a final meeting to discuss the lectures and enumerate any problems that arose in the classroom. Their impressions of the lectures were generally positive. As to workshop preparation, however, there were some negative responses due to the lack of assembly parts in the second workshop. On the other hand, the tutors evaluated the teaching and communication skills positively, as shown in Fig. 3. The tutors' comments were as follows:

- It was pretty fun to teach when the lecture was given.

- It was my first time to teach, so it was a very fresh and good experience.

- I was better able to understand the difficulty of teaching students.

- I was able to experience the challenge of teaching and understanding things.

- I had a valuable experience in teaching students and would like to take advantage of this experience in the future.

As indicated in the tutors' impressions, communication skills, teaching and coaching skills, and task competences are essential for creative engineers (Dym et al., 2005; Litzinger et al., 2011). This result suggests that the lecture designed by the authors made a meaningful contribution to the development of creative engineers.
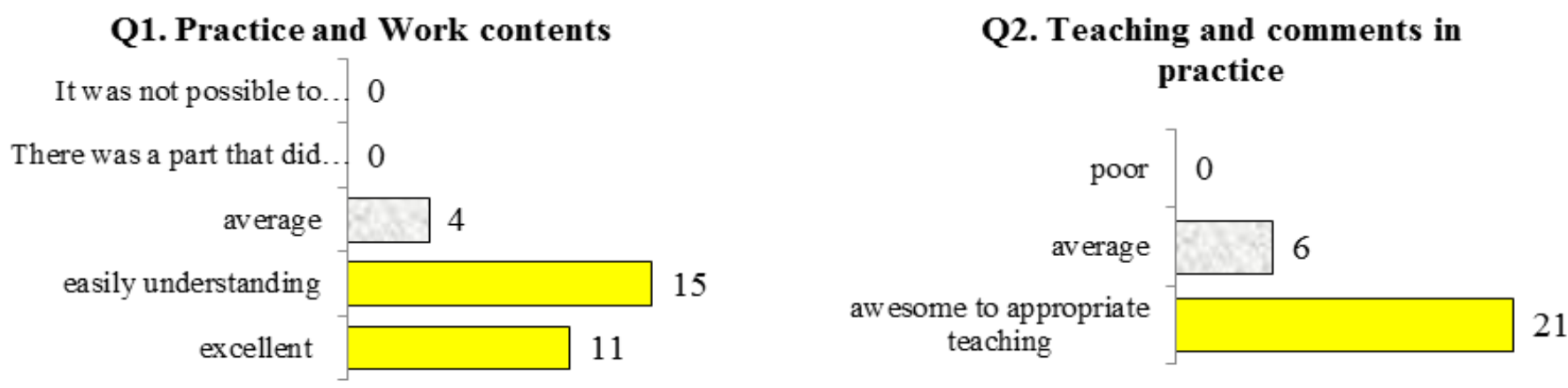

\section{Q3. Quality of the teaching slide}

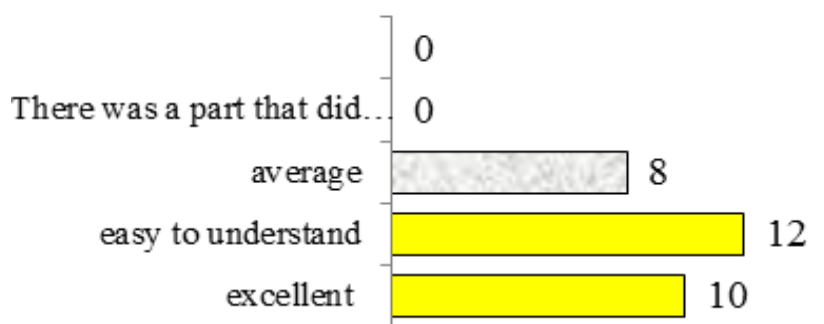

\section{Q4. Self-evaluation of the gyro bicycle}

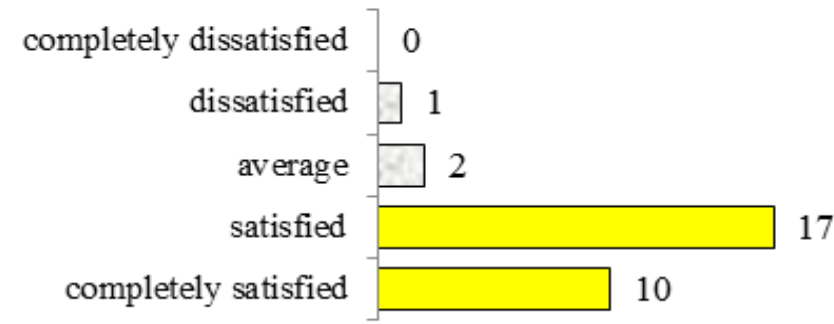

\section{Q5. Can you understand why a moving bicycle does not fall?}

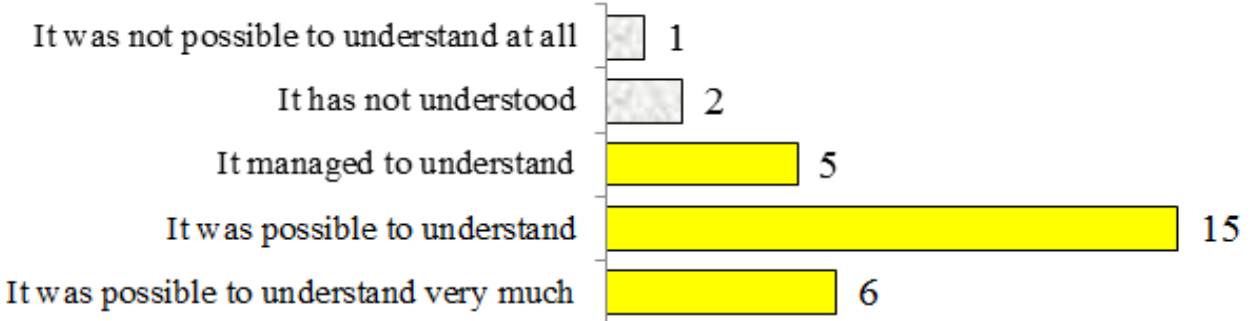

Figure-3. Results of the participant questionnaire. The items in the questionnaire were as follows: Q1: How was the quality of practice and work content?; Q2: How was the teaching skill and the comments regarding practice?; Q3: What was your impression of the slides? Q4: How satisfied are you with the gyro-bicycle that you created? Q5: What is you level of understanding of the gyro effect. Source: Tutor' Impression

\section{Conclusions}

This paper describes a summer school workshop for junior high-school students on the Dynamics of Machines using the fabrication of a gyro-bicycle. The workshop was presented by Okinawa KOSEN students who were registered in the "Creative Research" class.

After the workshop lecture, to confirm student satisfaction and their level of understanding of the principles taught in the lecture, a questionnaire was completed by the participants and the university students who served as workshop tutors. The results were as follows:

1. A number of comments were highly favorable with respect to the lecture slides, guidance and content.

2. The participants' level of understanding of the mechanical phenomena associated with the gyro effect was fairly good.

As instructors who were registered in the "Creative Research" course confirmed, to promote student understanding, communication and teaching skills are essential.

\section{References}

Araki, M., 2010. KOSEN: 5-year engineering education starting from age 15. IFAC Proceedings, 42(24): 326-331. View at Google Scholar $\mid$ View at

Dym, C.L., A.M. Agogino, O. Eris, D.D. Frey and L.J. Leifer, 2005. Engineering design thinking, teaching, and learning. Journal of Engineering Education, 94(1): 103-120. View at Google Scholar

EDU-Port Japan, 2017. Retrieved from https://www.eduport.mext.go.jp/en/ [Accessed 2017.12.06]. 
Higa, Y., O. Makishi, H. Toba and H. Yamashiro, 2010. A first year engineering education targeted fundamental physical sciences in Dept. Mechanical Systems Engineering, Okinawa National College of Technology -A Practical Example of Mechanics Education in OkNCT Seminar -, Proceedings of National College of Technology education lecture. pp: 489-492.

Kobatake, H., 2013. The past and the next-centuries of KOSEN. Journal of Japanese Society for Engineering Education, 61(1): 6-10. View at Publisher

Litzinger, T., L.R. Lattuca, R. Hadgraft and W. Newstetter, 2011. Engineering education and the development of expertise. Journal of Engineering Education, $100(1)$ : 123-150. View at Google Scholar $\mid$ View at Publisher

Murata, K., 2011. High school physics notebook. Tokyo: Kohgakusha.

National Institute of Technology Okinawa College, 2017. Retrieved from http://en.okinawa-ct.ac.jp/ [Accessed 2017.12.04].

Newby, H., T. Weko, D. Breneman, T. Johannesson and P. Maassen, 2009. OECD reviews of tertiary education Japan. Retrieved from www.oecd.org/publishing/corrigenda [Accessed 5th December 2013]. 